\title{
DIMENSÕES SEMIÓTICAS DA RELAÇÃO PROCESSUAL ${ }^{1}$
}

\section{SEMIOTIC DIMENSIONS OF THE PROCEDURAL RELATIONSHIP}

Yuri de Oliveira Dantas Silva Mestre em Direito pela Universidade Federal do Espírito Santo. Pós- Graduado em Filosofia e Teoria do Direito pela Pontifícia Universidade Católica de Minas Gerais. PósGraduado em Direito Tributário pelo Instituto Brasileiro de Estudos Tributários. Graduado em Direito pela Universidade Federal do Espírito Santo. Professor. Advogado. Vitória/ES. E-mail: yuriods@hotmail.com

RESUMO: O objetivo deste trabalho é a análise da relação processual a partir dos planos da linguagem. Como método é utilizada a Teoria Analítica da Norma Jurídica, nossa matriz epistemológica. A nível sintático destaca-se o mínimo formal da relação processual; a nível semântico às variáveis são atribuídos significados; a nível pragmático destaca-se o uso e a finalidade da relação processual.

PALAVRAS-CHAVE: Relação processual; Teoria Analítica da Norma Jurídica, Linguagem. Sintática, Semântica.

ABSTRACT: The objective of this work is to analyze the procedural relationship from its linguistic plans. As a method, the Analytical Theory of the Legal Norm, our epistemological matrix, is used. At a syntactic level, the formal minimum of the procedural relationship stands out; at the semantic level, variables are assigned meanings; at a pragmatic level, the use and purpose of the procedural relationship stands out.

KEYWORDS: Procedural Relation; Analytical Theory of the Legal Norm; Language, Syntactic, Semantic.

\footnotetext{
${ }^{1}$ Artigo recebido em 03/08/2020 e aprovado em 13/12/2020.
} 


\section{INTRODUÇÃO}

Esse é um trabalho localizado no ponto de contato entre a Teoria Geral do Direito e a Teoria Geral do Processo. Por "Teoria Geral do Direito" entendemos aquela porção linguístico descritiva onde ocorre a confluência das categorias jurídicas comuns a todos os ramos do direito positivo; "é o ponto de ligação entre todos os níveis de investigação sobre o direito."2. A Teoria Geral do Direito abarca a Teoria Geral do Processo. Essa irá concentrar os seus esforços no estudo das categorias processuais gerais que se repetem ao longo das normas processuais. Ambas fixam os seus conceitos jurídicos fundamentais, o que é condição da experiência jurídica.

O objeto de nossa investigação é a relação jurídica processual. Nosso objetivo é a análise do nosso objeto a partir dos planos sintático, semântico e pragmático em que ele se manifesta, tendo como método a Teoria Analítica da Norma Jurídica, proposta por Lourival Vilanova e Paulo de Barros Carvalho, que pressupõe o seguinte corte metodológico: direito-objeto como conjunto de enunciados prescritivos expedidos por autoridades credenciadas pelo sistema de direito positivo. As perguntas que guiam esse estudo são: i) qual é a estrutura da relação processual?; ii) quais os significados de suas constantes e variáveis?; iii) a que se destina a relação processual e como esse signo é usado pelo STJ?

As perguntas a serem respondidas correspondem, respectivamente, a investigações inerentes aos campos da: i)sintática; ii) semântica; iii) pragmática.

\section{I - Preliminar epistemológica: alguns conceitos da Semiótica}

A "linguagem" tardou a ingressar de maneira central no debate epistêmico. Antes o debate era marcado pela dualidade "experiência/razão". O mencionado embate, centrado

\footnotetext{
${ }^{2}$ VILANOVA, Lourival. Causalidade e Relação no Direito. 4.ed. São Paulo: Revista dos Tribunais, 2000. p.298.
} 
no eixo "razão-evento", $\mathrm{XX}$, ocasião em que surge o "Círculo de Viena". Com o referido movimento um importante ${ }^{5}$ elemento é posto em evidência para deixar ainda mais complexo esse embate epistemológico. Esse elemento é a "linguagem" e a ele é conferida ênfase central (deslocamento de foco, esse, conhecido como "giro linguístico"), sobretudo pelos Neopositivistas Lógicos.

Firmes no propósito do "giro linguístico", os Neopositivistas lógicos reduzem a Epistemologia à Semiótica ${ }^{6}$, que é entendida como a ciência dos signos, ou teoria geral dos signos. A Semiótica estuda os elementos representativos no processo de comunicação. Dito de outra maneira: a Semiótica estuda os signos. O signo expressa a relação de um fenômeno com outro fenômeno ${ }^{7}$. Uma coisa, A, é um signo de outra coisa, B. Costuma-se dizer que o signo sempre está no lugar de outra coisa; ele sempre aponta para algo distinto dele mesmo. A caída das folhas é um signo do outono; a sirene ligada do carro de bombeiros é signo de incêndio; a febre, espirros e fraqueza são signos de gripe; a palavra "livro" é signo daquele objeto que possui várias páginas sobrepostas, com capa e contracapa.

O signo, então, possui esse status lógico de relação. O signo (a rigor, o símbolo), a partir de Paulo de Barros Carvalho ${ }^{8}$, apresenta status lógico de relação, em que um suporte físico (palavra escrita ou falada) é associado a um significado ${ }^{9}$ (objeto do mundo exterior ou interior) ao qual o homem atribui uma significação (ideia criada pelo sujeito

\footnotetext{
${ }^{3}$ Racionalistas e Empiristas marcavam os dois extremos. O Empirismo confere aspecto central à experiência humana, aos eventos, "o conhecimento vem da experiência sensível". Já o Racionalismo confere aspecto central à razão, ou ideia; a inteligência humana seria responsável por ordenar esse material fático e interpretálo, daí viria o conhecimento. Entre essas posições extremas há as intermediárias, como o intelectualismo, de Aristóteles e o criticismo, de Immanuel Kant.

${ }^{4}$ ADEODATO, João Maurício. O problema do conhecimento do direito e a proposta retórica realista. DUC IN ALTUM cadernos de direito, v. 9, p. 71, 2017

${ }^{5}$ Importante, mas não novo, pois Platão escrevera "Crátilo" em 388 a.C., que é por muitos considerada a primeira obra de Filosofia da Linguagem

${ }^{6}$ CARVAlHO, Paulo de Barros. Direito Tributário: linguagem e método.4.ed.São Paulo:Noeses. 2011. p.21.

7 GHIGLIANI, Alejandro M.; GUARINONI, Ricardo V.; GUIBOURG, Ricardo A. Introducción al conocimiento científico. 3. ed. Buenos Aires: Eudeba, 2000. p.18.

${ }^{8}$ CARVALHO, Paulo de Barros. Direito Tributário: linguagem e método.4.ed.São Paulo:Noeses. 2011. p.33-34.

${ }^{9}$ Os elementos do significado são: conotação e denotação. Então o significado não é a coisa em si, mas, sim, critérios de uso de uma palavra de classe (conotação) ou elementos que preenchem os critérios de uso (denotação).
} 
cognoscente). Essa cisão (linguagem e realidade) ${ }^{10}$ gera importantes reflexos no Direito. Cai por terra a ideia de um sentido correto da "norma" ou de "extrair o sentido do texto", por exemplo, como se fosse possível chegar à sua essência ${ }^{11}$. Constata-se que o direito positivo (suporte físico) é absolutamente independente do sentido que a ele é atribuído (significação). Interpretar passar a ser visto como um ato de atribuir sentidos ao suporte físico.

O significado possui dois elementos: a conotação (critérios de uso de uma palavra) e a denotação (conjunto de elementos que cabem nessa palavra). Ambos estão em função recíproca $^{12}$; se a conotação se amplia, a denotação se restringe, já se a conotação contar com menos critérios de uso, a denotação será ampliada. Ora, se antes se exigia as propriedades A e B para que determinado objeto integrasse a classe conotada e agora se exige $\mathrm{A}, \mathrm{B}$ e $\mathrm{C}$, menos objetos caberão nessa classe, uma vez que as características ficam mais específicas. No Direito, por exemplo, podemos destacar o problema milenar da conotação e denotação de Justiça, problema, esse ligado ontologicamente à Filosofia do Direito.

Outro ponto que merece o nosso destaque é a diferença entre a linguagem-objeto e a metalinguagem. A linguagem-objeto, ou linguagem de nível $\mathrm{L}_{0}$ é descrita pela metalinguagem $\mathrm{L}_{1}$, ou linguagem de sobrenível. A metalinguagem dirige-se à linguagem de nível para descrevê-la ${ }^{13}$. Não há nenhuma interferência entre esses níveis. Quando o

\footnotetext{
${ }^{10}$ A linguagem não toca a realidade; são mundos não intersseccionáveis; o que se fala a respeito da coisa não é a coisa. Essa distinção leva Samuel Hayakawa a afirmar que "o símbolo não é a coisa simbolizada; O mapa não é o território; a palavra não é a coisa." (HAYAKAWA, Samuel. A linguagem no pensamento e na ação. São Paulo:Pioneira, 1977. p. 35.)

${ }^{11}$ A respeito da oposição entre a tese realista (ou essencialista) e a nominalisa, Warat explica: “(...)existe uma postura de larga tradição que sustenta que o significado dos termos está determinado pela realidade. Essa linha deriva de Platão, que sustenta que o significado das palavras devia refletir aquelas características que constituíam a essência da coisa. [essa é a tese realista]. Por contraposição surgem as chamadas teses nominalistas, que negam que possa existir uma relação natural entre as palavras e aquilo que elas pretendem significar. Afirmam, pelo contrário, que a relação aludida atende a um processo convencional." (WARAT, Luis Alberto. A definição jurídica.1.ed. Porto Alegre: Atrium, 1977. p. 3). Neste mesmo sentido: "NINO, Carlos Santiago. Introdução à análise do direito.1.ed.São Paulo: Martins Fontes, 2010, p. 292-296.”. O autor, cita Jorge Luiz Borges: "Se o nome é o reflexo da coisa (como diz o grego no Crátilo), nas letras de 'rosa' está a rosa e todo o Nilo na palavra 'Nilo'."

${ }^{12}$ NINO, Carlos Santiago. Introdução à análise do direito.1.ed.São Paulo: Martins Fontes, 2010, p. 297.

13 "A respeito dos níveis de linguagem: GHIGLIANI, Alejandro M.; GUARINONI, Ricardo V.; GUIBOURG, Ricardo A. Introducción al conocimiento científico. 3. ed. Buenos Aires: Eudeba, 2000.p.28.”; VILANOVA, Lourival. Estruturas Lógicas e o Sistema de Direito Positivo.3.ed.São Paulo: Noeses, 2005.p.242. Vilanova opera especificamente com esse objeto em : Níveis de linguagem em Kelsen. In: . Escritos jurídicos e filosóficos. São Paulo: IBET, 2003.v.2.
} 
sujeito fala acerca da linguagem ele estará inserido em nível metalinguístico. Mas essas noções são relativas, uma vez que o quê for tido como metalinguagem num ponto dessa cadeia de análise, pode ser tido como linguagem-objeto em outro ponto. Um tratado de semiótica é metalinguagem, mas pode ser tido como linguagem-objeto se sobre ele forem tecidas considerações descritivas.

A Linguagem pode ser analisada por três planos distintos, cada qual com um objeto próprio, quais sejam: o sintático, o semântico e o pragmático. O estudo da dimensão sintática da Linguagem direciona a sua atenção para a relação entre os signos; a semântica estuda a relação entre o suporte físico e o objeto designado; e a pragmática estuda a relação do suporte físico com seu utente. Isso nos permite afirmar que o sistema de direito positivo é fechado sintaticamente (só se altera mediante normas jurídicas), mas aberto do ponto de vista da semântica (interpretação) e pragmática (uso) ${ }^{14}$.

Tudo dito acima se aplica in totum ao Direito (e a qualquer outro conjunto de enunciados). Os reflexos são nítidos. O direito positivo é definido, neste trabalho, como "um conjunto de enunciados prescritivos expedidos por autoridades competentes" $\left(\right.$ suportes físicos) ${ }^{15}$, que regem a conduta humana (significado) ${ }^{16}$; o direito positivo ocupa o nível de linguagem-objeto, ao passo que a Ciência do Direito é metalinguagem, visa descrevê-lo. O direito positivo é analisado a partir de seus três planos: o sintático, o semântico e o pragmático.

Esses são os aspectos da Semiótica que serão mais úteis para nós no decorrer do desenvolvimento do presente trabalho.

\section{II - A relação jurídica processual: análise sintática}

\section{II.I - Teoria analítica da Norma Jurídica}

\footnotetext{
${ }^{14}$ Com relação ao fechamento e abertura do sistema de direito positivo: SILVA, Yuri de Oliveira Dantas. Anulação e Controle das Normas Jurídicas: uma análise a partir da Ação Direta de Inconstitucionalidade. 1.ed. Campo Grande: Contemplar, 2017. p. 67-75

${ }^{15} \mathrm{O}$ direito positivo é signo do tipo símbolo. Há, ainda, o índice e o ícone. Mas essa classificação sígnica não será abordada neste trabalho. A respeito dessa distinção, levada a cabo por Charles S. Peirce: "CARVALHO, Paulo de Barros. Direito Tributário: linguagem e método.4.ed.São Paulo:Noeses. 2011. p.35.”

16 Clarice Araújo enuncia que: "As leis, como signos que são, referem-se a objetos. Genericamente considerado, o objeto das leis jurídicas é a conduta humana em sociedade." (ARAUJO, Clarice von Oertzen de. Semiótica e investigação do Direito. In: Paulo de Barros Carvalho; Aurora Tomazini de Carvalho. (Org.). Constructivismo Lógico-Semântico. Volume I. 1ed.São Paulo: Editora Noeses, 2014, v. 1, p. 123.
} 
Como vimos, a sintática é um plano da Semiótica que estuda a relação entre os signos, com independência de seu significado (conotação/denotação). Abstrai-se o fático, o empírico; esvazia-se o conteúdo. Neste tópico II estudaremos a estrutura da relação jurídica processual, logo, restingir-nos-emos a decompô-la logicamente a fim de demonstrar a sua estrutura lógico-sintática bem como as suas características. Faremos esse estudo a partir da Teoria da Norma Jurídica, proposta por Lourival Vilanova e desenvolvida por Paulo de Barros Carvalho.

O primeiro aspecto que merece ser destacado é, novamente, a distinção entre o texto (suporte físico) e a ideia que ele forma no intérprete (significação). O direito positivo é formado por um conjunto de enunciados $\operatorname{prescritivos}^{17}$ ejetados no sistema por autoridades credenciadas - nosso corte metodológico - e a partir da leitura destes constróise o seu sentido. Há dois planos ontologicamente distintos: o plano da expressão (empírico) e o plano proposicional (juízo). No plano proposicional é que se constrói o sentido dos enunciados prescritivos. Essa distinção nos é útil para traçarmos a distinção entre enunciados prescritivos (lei, artigo de lei, parágrafos, incisos etc) e a norma jurídica, construída em nível proposicional, de juízo.

O intérprete se depara com uma gama de enunciados prescritivos e de sua leitura ele forma, em nível proposicional, a norma jurídica - estrutura lógico-sintática. A norma jurídica aparece, então, como uma estrutura epistemológica de aproximação do sujeito cognoscente em relação ao seu objeto de estudos. Mas não é qualquer juízo que é suficiente para que se construa a norma jurídica, pois a mesma possui a estrutura implicacional. Daí afirmarmos que a norma jurídica é um juízo implicacional: ${ }^{18}(\mathrm{H} \rightarrow \mathrm{C})$.

A significação deve ter um sentido normativo (ou deôntico) para que falemos em "norma jurídica", deve ser um juízo hipotético-condicional, i.e., a forma da implicação deve estar presente para que se diga que uma norma jurídica foi construída. Essa forma, que permeia todo o direito, é “Se...,então...". Se acontecer a hipótese X, então deve ser a consequência Y. Essa é a estrutura que a norma jurídica obedece. Isso nos permite concluir

\footnotetext{
${ }^{17} \mathrm{O}$ mesmo dado material "O" pode ser reconstruído em diversos objetos formais $\mathrm{O}$ ', O", $\mathrm{O}^{\mathrm{n}}$ ' tantas quantas forem as possibilidades interpretativas inventadas pelos sujeitos cognoscentes (I', I', $\mathrm{I}^{\mathrm{n}}$ ). O objeto de estudos é sempre formalmente constituído.

${ }^{18}$ CARVALHO, Paulo de Barros. Curso de Direito Tributário.22.ed.São Paulo: Saraiva, 2010. p. 40-42.
} 
que não é toda significação construída a partir da leitura de enunciados prescritivos que será suficiente para a construção de uma norma jurídica; a significação deve obedecer a forma implicacional "se...,então...". Por exemplo, da leitura do enunciado "Brasília é a Capital Federal." ou "revogam-se as disposições em contrário", não se constrói nenhuma norma jurídica, mas, sim, significações isoladas.

A norma jurídica é, assim, a unidade completa de significação do deôntico jurídico obtida pela formalização do direito positivo; é o resultado desse processo intelectual onde se visa alcançar a forma implicacional.

A estrutura lógico-sintática da norma jurídica (se A, então deve ser B) é composta por variáveis e por constantes. Alcança-se a estrutura lógica da norma jurídica por meio de sucessivos processos de generalização e por fim de formalização ${ }^{19}$, tendo como ponto de partida para tal processo os enunciados prescritivos que compõem o objeto "direito positivo". Neste estágio não trabalharemos inseridos campo de irradiação semântica dos signos, mas tão-somente com categoremas e sincategoremas, ou, variáveis e constantes.

A norma jurídica completa consta de duas partes: norma primária e norma secundária. A norma primária é de direito material, em que são prescritos direitos e deveres e a norma secundária é de direito processual, ou sancionadora. Ambas são compostas por um antecedente unido ao consequente por um functor deôntico. Operaremos, neste estudo, com a estrutura lógica da norma jurídica criada por VILANOVA, que pode ser assim representada:

\section{$\mathrm{D}\left\{\left[\mathrm{H} \rightarrow \mathrm{R}\left(\mathrm{S}^{\prime}, \mathrm{S}^{\prime \prime}\right)\right] \mathrm{v}\left[-\mathrm{R}\left(\mathrm{S}^{\prime}, \mathrm{S}^{\prime \prime}\right) \rightarrow \mathrm{R}{ }^{\prime}\left(\mathrm{S}^{\prime}, \mathrm{S}^{\prime}, \mathrm{S}^{\prime},{ }^{\prime}\right)\right]\right\}$}

Essa fórmula é uma reconstrução formal do que na linguagem dos enunciados prescritivos se apresenta complexo e disperso. A mencionada construção resulta de uma abstração lógica onde se trabalha apenas a nível sintático-formal, onde se suspende as referências semânticas e onde se opera apenas com a estrutura lógica da norma jurídica ${ }^{20}$.

\footnotetext{
${ }^{19}$ Com relação à abstração e formalização: VILANOVA, Lourival. Causalidade e Relação no Direito. 4.ed. São Paulo: Revista dos Tribunais, 2000. p.74 - 75; VILANOVA, Lourival. Estruturas Lógicas e o Sistema de Direito Positivo.3.ed.São Paulo: Noeses, 2005. p. 49-51; CARVALHO, Paulo de Barros. Direito Tributário: linguagem e método.4.ed.São Paulo:Noeses. 2011. p.99.

${ }^{20}$ Em breve síntese, Lourival Vilanova nos explicita o sentido das constantes e variáveis de sua estrutura lógica da norma jurídica: "Em cada norma-parte, temos hipótese fáctica e consequência. Na primeira, o suporte fáctico é fato natural ou humano (evento/conduta); na segunda, o suporte fáctico é a não-verificação da consequência da primeira norma.[...] Podemos, em reescritura abstrata, delinear o esquema da norma jurídica assim: se se dá o fato $F$, então o sujeito $S$ ' fica em relação R com o sujeito $S$ ', (norma primária); se
} 
Antes do disjuntor includente (v) há a estrutura da norma primária, após, a estrutura da norma secundária. A norma primária tem como seu referencial a gama de enunciados ligados ao direito material (civil, penal, tributário, comercial etc), ao passo que a norma secundária é tida como a norma sancionadora, ou norma processual. A sanção só pode ser imposta pelo Estado-Juiz se algumas regras foram seguidas. Essas regras a serem seguidas são as chamadas regras processuais, daí a equivalência entre norma sancionadora e norma processual. Neste ponto é importante destacar que as normas de direito processual são normas meio, ou instrumentais, em comparação com as normas de direito material ${ }^{21}$.

As duas normas (primária e secundária) têm em sua estrutura lógica a parte antecedente e a parte consequente. Como dito acima, as normas possuem a forma implicacional. Na norma primária o antecedente descreve um fato (ou uma conduta/fato da natureza) de possível ocorrência, em certo espaço e em certo tempo - prescrever algo impossível de ocorrer é um sem sentido semântico. Ocorrido o fato, pela força da causalidade normativa, é constituída uma relação jurídica material, que é o consequente normativo da norma primária. Essa é a norma primária. A norma secundária tem em seu antecedente a negativa da relação jurídica material (ilícito jurídico) e a ele é vinculado o consequente da norma secundária, que é a relação processual, ou relações processuais, como adiante analisaremos.

A partir da leitura da estrutura lógica da norma jurídica constata-se que a "relação jurídica" aparece em três momentos distintos. Neste ponto é pertinente uma observação: a

S' não faz ou faz o que devia não fazer ou omitir, então o sujeito $S$ ', tem o poder de exigir a observância da conduta devida perante S', (relação R' na norma secundária).” (VILANOVA, Lourival. Causalidade e Relação no Direito. 4.ed. São Paulo: Revista dos Tribunais, 2000. p.74.)

${ }^{21}$ Segundo Antonio Carlos Cintra, Ada Pellegrini e Cândido Dinamarco, "O direito processual é, assim, do ponto-de-vista de sua função jurídica, um instrumento a serviço do direito material: todos os seus institutos básicos (jurisdição, ação, exceção, processo) são concebidos e justificam-se no quadro das instituições do Estado pela necessidade de garantir a autoridade do ordenamento jurídico." (CINTRA, Antonio Carlos de Araújo; DINAMARCO, Cândido Rangel; GRINOVER, Ada Pellegrini. Teoria Geral do Processo. $24^{\mathrm{a}}$ ed. São Paulo: Malheiros, 2008.p. 46). Estes autores, quando enunciam a respeito do caráter instrumental do "processo", os aspectos positivos e negativos da instrumentalidade são desenvolvidos: o sentido positivo da instrumentalidade reside na necessidade de efetividade do processo, ou seja, deve haver um sistema processual apto a atingir a ordem jurídica justa; já em seu sentido negativo, a instrumentalidade faz o processo ser enxergado não como um fim em si mesmo, ou seja, os direitos materiais não podem ser contrariados por uma observância cega às formas. "CINTRA, Antonio Carlos de Araújo; DINAMARCO, Cândido Rangel; GRINOVER, Ada Pellegrini. Teoria Geral do Processo. 24 ${ }^{\mathrm{a}}$ ed. São Paulo: Malheiros, 2008.p. 47- 48.) 
relação jurídica processual é uma relação jurídica e ambas são, antes de tudo, uma relação, razão pela qual as características traçadas adiante se aplicam a todas as relações jurídicas.

\section{II.III - Relação jurídica: a sua estrutura e o contraste entre relação jurídica material e relação jurídica processual}

Em grau maior de abstração, onde há o desprendimento do referencial semântico, temos, então, a relação jurídica como relação, logo, obediente ao mínimo estrutural da "relação". Isso nos permite analisar a relação jurídica como “(...)estruturas formais, compondo-se de um termo antecedente (ou termo referente) e de outro termo consequente (ou termo relato) e, ainda, de uma espécie de operador: o operador relacionante."22

Assim, a relação é composta minimamente por três variáveis. Duas variáveis de sujeitos (substituímos " $x$ " e " $y$ " por $S$ ' e $S$ ") e uma variável relacional (R), como dito acima. Os sujeitos-de-direito $S$ ' e $S$ " são unidos sintaticamente por essa variável "R" que poderá ser modalizada pelos functores obrigatório $(\mathrm{O})$, proibido $(\mathrm{Ph}$ ou $\mathrm{V})$ e permitido $(\mathrm{P})$. Não há a quarta possibilidade; tríplice é a modalidade deôntica. Esses modais do dever-ser são irredutíveis, mas interdefiníveis; define-se um pelo outro. Por exemplo: caso se proíba (V) certa conduta (p), constata-se a equivalência de $\mathrm{V}(\mathrm{p})$ a $\mathrm{O}(-\mathrm{p})$ e $-\mathrm{P}(\mathrm{p})^{23}$.

Estar em relação jurídica significa que $S$ ' terá o direito subjetivo ${ }^{24}$ de exigir a conduta $^{25}$ "p" por parte de $\mathrm{S}$ ". Este, por sua vez, terá o dever jurídico de conduzir-se da

\footnotetext{
${ }^{22}$ VILANOVA, Lourival. Causalidade e Relação no Direito. 4.ed. São Paulo: Revista dos Tribunais, 2000. p. 116 - 117. Marcos Bernardes de Mello também opera com essa estrutura e inclui o que chama de "conteúdo eficacial da relação jurídica". Ao sujeito ativo são atribuíveis: direito, pretensão, ação; ao sujeito passivo são atribuíveis os correlatos: dever, obrigação e situação de acionado. (MELLO, Marcos Bernardes de. Teoria do fato jurídico: plano da eficácia. $1^{a}$ parte. 12.ed.São Paulo: Saraiva, 2003. p. 170, 182-186.)

${ }^{23}$ Três são os functores relacionais, irredutíveis, mas todos eles interdefiníveis. Desta maneira, com o auxílio do conectivo negador (-) há a interdefinição entre os functores, por exemplo: $\mathrm{O}(\mathrm{p}) \equiv-\mathrm{P}(-\mathrm{p})$, o que significa: dizer que uma conduta "p" é obrigatória equivale a afirmar que não é permitido omiti-la. A partir da predicação de uma conduta em uma das três modalidades deônticas, é possível a dedução para se saber quais são as suas consequentes, ou correlatas modalizações. Elas se equivalem. A respeito da interdefinibilidade, ou equivalência, dos modais deônticos, Guibourg, Echave e Urquijo nos apresentam o seguinte esquema: "Pp $\equiv-\mathrm{O}-\mathrm{p} \equiv-\mathrm{Ph} \mathrm{p} ;-\mathrm{Pp} \equiv \mathrm{O}-\mathrm{p} \equiv \mathrm{Ph} \mathrm{p} ; \mathrm{P}-\mathrm{p} \equiv-\mathrm{Op} \equiv-\mathrm{Ph}-\mathrm{p} ;-\mathrm{P}-\mathrm{p} \equiv \mathrm{Op} \equiv \mathrm{Ph}-\mathrm{p}$ " (ECHAVE, Delia; URQUIJO, María; GUIBOURG, Ricardo. Lógica, proposición y norma.1.ed.Buenos Aires: Editorial Astrea, 2002. p. 123.). Cumpre destacar que os juristas argentinos usam o símbolo " $\mathrm{Ph}$ " com o sentido de "proibido", modalidade deôntica que pode aparecer como "V".

${ }^{24}$ Sobretudo a partir de Léon Duguit critica-se o conceito de "direito subjetivo", sob o argumento de que seu conceito é metafísico, para que se possa operar com o conceito de "situação jurídica", nomenclatura amplamente difundida. (GOMES, Orlando. Introdução ao Direito Civil. 20.ed. Rio de Janeiro: Forense,
} 
forma "p", conduta, essa, que sempre será, como dito acima, proibida, permitida ou obrigatória. ${ }^{26}$ Podemos representar graficamente a relação jurídica da seguinte maneira:

A relação jurídica é estruturada da seguinte forma:

$\mathrm{S}^{\prime}$ $\mathrm{R}^{\prime}$ $\mathrm{S}^{\prime}$

Direito subjetivo

Dever jurídico

Essa é a estrutura da relação jurídica de direito material, relação binária fundada em fatos jurídicos cujas normas de incidência a ele ligam efeitos materiais. A relação jurídica de direito material terá duas partes, ou dois termos, sujeitos-de-direito, unidos sintaticamente pelo functor "R". Essas partes possuem a subjetividade de direito material, cada qual com direitos subjetivos (pretensão) e deveres jurídicos (obrigação), para ficarmos com o exemplo de direito civil. As partes serão duas, ainda que internamente cada parte componha-se de uma pluralidade de pessoas (como nas obrigações solidárias, por exemplo). ${ }^{27}$

A relação jurídica material é horizontal, unilinear, bimembre e tem como objeto as condutas advindas de normas de direito material, ou, normas primárias.

A relação jurídica processual completa tradicionalmente é, figuradamente, uma relação angular, que corresponde ao consequente da norma secundária. Angular porque ela é composta por duas relações jurídicas processuais: exercício de direito de ação (Autor) e exercício de direito de exceção, ou defesa (Réu). O termo comum dessa dúplice relação processual é o órgão jurisdicional (que concentra o emprego da coação); o Estado-Juiz é o

2010.p.85). Não é cabível neste trabalho essa discussão, uma vez que operamos o direito subjetivo como uma projeção do direito objetivo; aquele advém deste.

${ }^{25} \mathrm{O}$ que se exige, em relação jurídica, é conduta (dar, fazer, não fazer), uma vez que o direito positivo rege o plexo de relações humanas, em certo tempo e espaço, razão pela qual não há que se falar em: a) relação jurídica entre pessoa e coisa; b) relação jurídica entre pessoa e lugar; c) relação jurídica entre coisa e coisa, d) relação jurídica da pessoa consigo mesma e e) existência de direito sem sujeito. Como bem aduz Marcos Bernades de Mello, "(...)essas categorias não têm consistência científica, pois se fundamentam em aparências fáticas.” MELLO, Marcos Bernardes de. Teoria do fato jurídico: plano da eficácia. $1^{\mathrm{a}}$ parte. 12.ed.São Paulo: Saraiva, 2003. p.173.

${ }^{26}$ Segundo Marcos Bernardes de Mello: "Em todo o campo do direito, sempre que se menciona haver um direito, um dever, uma pretensão, uma obrigação ou qualquer outra categoria eficacial, estar-se-á, em geral, diante de uma relação jurídica, porque haverá sujeitos de direito, um em face do outro(...)": MELLO, Marcos Bernardes de. Teoria do fato jurídico: plano da eficácia. $1^{\text {a }}$ parte. 12.ed.São Paulo: Saraiva, 2003. p.170.

${ }^{27}$ VILANOVA, Lourival. Causalidade e Relação no Direito. 4.ed. São Paulo: Revista dos Tribunais, 2000. p.204. 
ponto de confluência entre as duas relações processuais. A relação processual, segundo VILANOVA ${ }^{28}$ é trinária: R'(S',S',,$\left.S^{\prime}{ }^{\prime \prime}\right)^{29}$, ou seja, é estabelecida com três termos. Apesar dessa representação da relação processual, penso ser mais adequado representá-la da seguinte maneira: $\mathrm{R}^{\prime \prime}\left\{\left[\mathrm{R}^{\prime}\left(\mathrm{S}^{\prime}, \mathrm{S}^{\prime \prime}\right)\right],\left[\mathrm{R}^{\prime}{ }^{\prime}\left(\mathrm{S}^{\prime},{ }^{\prime}, \mathrm{S}^{\prime}\right)\right]\right\}$. Isso porque, como visto, não há relação processual entre Autor e Réu, e o que existe não é uma relação apenas, como o esquema R'(S',S', $\left.S^{\prime \prime \prime}\right)$ nos sugere, mas duas: relação processual primária e relação processual secundária. Há uma relação entre relações, ou, relação de segunda ordem. ${ }^{30}$

A relação processual completa é formada por Autor, Réu e Estado-Juiz, gerando, assim, um esquema angular. Pode-se representar o mencionado esquema da seguinte maneira:

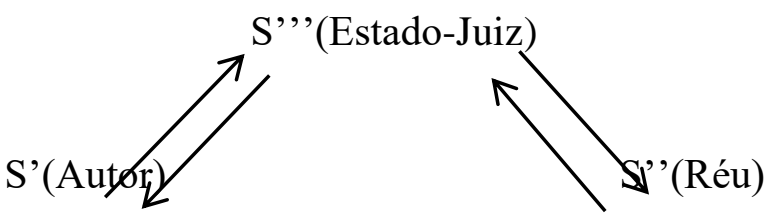

Trinária, angular, composta por duas relações processuais, regida por normas de direito processual, essa é a relação processual completa. Como se analisa acima, não há relação processual entre as partes. A relação que eles podem constituir é uma relação de direito material, jamais constituem uma relação de direito processual entre si. A relação jurídica processual sempre terá como um dos termos o Estado-Juiz. E é em direção a ele que as pretensões são formuladas e a defesa exercida.

${ }^{28}$ VILANOVA, Lourival. Causalidade e Relação no Direito. 4.ed. São Paulo: Revista dos Tribunais, 2000. p.195.

${ }^{29}$ Constatamos grande dificuldade de analisar uma relação jurídica com três termos (Autor, Réu e Juiz) e um operador relacionante, ou "R(S', S', S'"), isso porque: 1 - há duas relações processuais que compõem a chamada relação processual completa (Autor e Estado-juiz e Estado-juiz e Réu), logo, são dois functores relacionais R' e R', e não apenas um, como exposto mais acima; 2 - Lourival Vilanova mesmo - que defende a relação trinária - afirma Autor e Réu não firmam relação processual entre si, mas, sim, com o Estado-Juiz (VILANOVA, Lourival. Causalidade e Relação no Direito. 4.ed. São Paulo: Revista dos Tribunais, 2000. p.204). A estrutura R(S', S", S"') nos leva a equívoco, pois Autor e Réu não se relacionam entre si no seio de uma relação processual; 3 - a estrutura triádica não explicita em face de quem os direitos subjetivos e deveres jurídicos são exercidos.

Pensamos ser mais coerente operar com duas relações processuais - a primária (Autor e Estado-juiz) e a secundária (Réu e Estado-juiz), apenas, mas isso não será feito. Até seria coerente nomear a chamada relação processual completa de esquema relacional-processual completo, pelos motivos acima expostos, mas iremos usar a denominação relação processual completa (soma das relações processuais primária com a secundária), dada a maior simplicidade de se operar com este termo.

Por esses motivos penso ser mais coerente representar a relação processual completa com a seguinte forma:

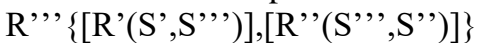

${ }^{30}$ A respeito das relações de primeira e de segunda ordem cf. CARVALHO, Paulo de Barros. Direito Tributário: linguagem e método.4.ed.São Paulo:Noeses. 2011. p. 101. 
Mas o que significa a relação processual? Quais os direitos e deveres que se constroem a partir dela? O que significa dizer que o Autor constituiu uma relação processual com o Estado-Juiz a partir do ato processual "petição inicial" e o Estado-Juiz, a partir do ato processual "citação" constituiu outra relação com o Réu? Essas questões estão ligadas a uma análise semântica da relação jurídica processual, que será o nosso próximo tópico.

\section{III - A relação jurídica processual: análise semântica}

A semântica é a Ciência do significado, ou seja, estuda a relação entre o suporte físico e o objeto designado. Ao cientista cumpre reduzir as complexidades de seu objeto de estudos, eliminando as ambiguidades (problema do sentido) e reduzindo a vaguidade (problema do alcance), propriedades do significado. O direito positivo (objeto) usa o mesmo suporte físico com significados diferentes (problema constante na doutrina também). Ao cientista cabe analisar essa miscelânea de significados e cortar, linguisticamente, o seu objeto de estudos, criando critérios de uso (conotação) para aquele signo, previamente - pacto semântico -, atitude, essa, que reduzirá bastante os problemas "científicos". Neste tópico nossos esforços serão destinados à análise semântica da relação jurídica processual.

Em toda relação jurídica há a figura do titular do direito subjetivo e do portador do dever jurídico. Direito subjetivo e dever jurídico co-existem ${ }^{31}$. Não é possível falar de um sem o outro, pois ao direito subjetivo contrapõe-se o dever jurídico. Assim, só há relação jurídica com esse mínimo sintático: termo-sujeito ativo com direito subjetivo, termosujeito passivo com dever jurídico e o vínculo, ou functor relacional "R".

Com a relação jurídica processual não é diferente. A sua ontologia obedece a esse mínimo formal. A "relação jurídica processual primária” é instaurada com o ato processual denominado "petição inicial", que pode ser reduzido à estrutura " $p \rightarrow q$ ", também, uma vez que nela o advogado narra um fato da vida (causa de pedir) e a esse fato é imputada uma

\footnotetext{
${ }^{31}$ MELLO, Marcos Bernardes de. Teoria do fato jurídico: plano da eficácia. $1^{a}$ parte. 12.ed.São Paulo: Saraiva, 2003. p.180.
} 
consequência jurídica. Esse ato tem como consequência jurídica a instauração da relação processual entre o Autor e o órgão jurisdicional, ou Estado-Juiz. ${ }^{32}$

A partir do momento em que o Autor ingressa com a petição inicial surge o dever jurídico do Estado-Juiz, qual seja, o dever de prestação jurisdicional. Assim já temos os correlatos: o Autor (termo $S$ ' da relação processual) tem o direito subjetivo de acionar o Estado-Juiz (ou direito de ação) e o Estado-Juiz (termo $\mathrm{S}^{\text {", }}$ da relação processual) tem o dever jurídico de prestação jurisdicional, e não de tutela jurisdicional, uma vez que é possível que sequer exista "direito" a ser tutelado ${ }^{33}$. O Autor tem, assim, o direito subjetivo a obter uma resposta do Estado-Juiz, seja de procedência, seja de improcedência de seu pedido. A classe "direito de ação" comporta não somente o direito de elaborar a petição inicial, mas se prolonga por toda a relação processual. Atos como o direito à produção de provas, a que a sentença seja fundamentada, ou de ser intimado para se manifestar a respeito dos atos processuais praticados pela parte contrária estão abarcados por essa classe.

Em rigor, a partir da perspectiva aqui adotada, o que se pede em sede de petição inicial é sempre a constituição de uma relação jurídica, com a consequente especificação de seus modais deônticos, isso porque a partir da leitura do suporte físico "sentença" ou "acórdão", sempre será constituída uma, ou algumas, relações jurídicas; relação jurídica constituída pelo Estado-Juiz. Relação jurídica, essa, que possui efeitos materiais, mas que foi constituída processualmente: relação processual-material.

O destinatário da petição inicial protocolizada, que instaura a relação jurídica processual, não é o Réu (que nesse momento sequer é Réu), mas, sim, o Estado-Juiz. É ao

\footnotetext{
${ }^{32}$ Não há necessidade de "angularização" para que exista a relação processual. Neste sentido: "A relação jurídica processual, em caso de angularidade necessária, forma-se entre autor e juiz e juiz e réu. A angularidade, como se pode concluir, não é essencial à caracterização da relação jurídica processual, mas necessária, sempre que há reu." (MELLO, Marcos Bernardes de. Teoria do fato jurídico: plano da eficácia. $1^{\text {a }}$ parte. 12.ed.São Paulo: Saraiva, 2003. p.212.)

${ }^{33}$ Neste sentido explicita Humberto Theodoro Júnior: "A ação, na verdade, é o direito à prestação jurisdicional e não necessariamente à tutela jurisdicional." (THEODORO JR, Humberto. Processo Cautelar. 25.ed. São Paulo: LEUD, 2010. p. 14). O que o Autor pede é a tutela jurisdicional, mas o dever do Estado é de prestação jurisdicional, pois em algumas situações sequer há direito a ser tutelado. $O$ presente autor, nessa linha, assevera que: "Embora a parte tenha que invocar uma situação jurídica material de que se afirme titular, o direito à prestação jurisdicional não está subordinado à efetiva existência do direito material arguido. Como direito à jurisdição, tem o direito de ação até mesmo aquele que sai derrotado pelo provimento jurisdicional.”( THEODORO JR, Humberto. Processo Cautelar. 25.ed. São Paulo: LEUD, 2010. p. 14)
} 
Estado-Juiz que se direciona o pedido de prestação jurisdicional. Esse é o dever do EstadoJuiz. Dito de outra maneira, o Autor exerce o direito subjetivo de ação perante o EstadoJuiz. Nesse sentido explicita VILANOVA ${ }^{34}$ : “O exercício do direito subjetivo de ação não tem como destinatário o sujeito passivo da relação. Dirige-se ao Estado, mediante seu órgão julgador."

O Réu não tem nenhum dever ou direito subjetivo perante o Autor no seio da relação processual, nem o Autor perante o Réu. Não há nenhum vínculo jurídico entre as partes (Autor e Réu) em âmbito processual. O vínculo deôntico-jurídico que os une é de direito material. Em âmbito processual ambas as partes se relacionam apenas com o Estado-Juiz.

Constituída a relação processual primária e satisfeitas as condições jurídicas para que o Réu possa ser citado, o Estado-Juiz realiza o ato processual denominado "citação". O ato "citação" inaugura a relação processual entre o Estado-Juiz e o Réu. O nome atribuído a essa relação, para fins de evitar a ambiguidade, será "relação processual secundária". Como relação que é, a relação processual secundária contém o "direito subjetivo" e "dever jurídico”. Quem possui o dever jurídico é o Estado-Juiz, que, em primeiro momento, é o dever de citar o Réu. Cumpre destacar que esse dever de citar está abrangido pela classe “dever de prestação jurisdicional”, que é o dever do Estado-Juiz no desenvolvimento de toda relação processual. O Réu, por sua vez, tem o direito subjetivo de contraditar, de se defender. Mais uma vez, essa defesa é exercida perante o Estado-Juiz, não perante o Autor da demanda. O direito subjetivo de se defender, tal como o direito de ação, não desaparece com o ato processual "contestação", ele se prolonga até a extinção da relação processual secundária. ${ }^{35}$

Pois bem, é importante, neste ponto, elucidarmos os significados dos termos da relação processual (S', S', S','). Nomeamos, antes, S' como Autor, S', como Réu e S', como Estado-Juiz. Cumpre destacar que, tal como na relação jurídica de direito material,

\footnotetext{
${ }^{34}$ VILANOVA, Lourival. Causalidade e Relação no Direito. 4.ed. São Paulo: Revista dos Tribunais, 2000. p. 204.

${ }^{35}$ Lourival Vilanova, uma das matrizes usadas aqui, sintetiza o que fora dito neste tópico: "Ao direito de ação contrapõe-se o direito de defesa. No exercício de um e de outro, os sujeitos dirigem-se ao Estado-juiz, com este constituindo relação: o exercício do direito de ação provoca no órgão julgador o dever jurisdicional de acolher o pedido, o dever de praticar o ato processual - despachar e mandar citar o sujeito passivo. $\mathrm{O}$ exercício do direito de defesa dirige-se ao juiz e outra relação linear se constitui(...)"(VILANOVA, Lourival. Causalidade e Relação no Direito. 4.ed. São Paulo: Revista dos Tribunais, 2000. p. 190)
} 
S' e S', internamente, no seio da relação processual, podem ter como seu referencial semântico uma pluralidade de sujeitos-de-direito, como no caso dos litisconsórcios ${ }^{36}$.

A análise dos termos da relação processual (S' e S', exclusivamente) nos remete à análise da legitimidade. Quem deve exercer o direito subjetivo de acionar o Estado é a parte legítima (que possuirá legitimidade ativa) e o Estado-Juiz (que deve ser competente) realizará o ato processual "citação" em face do Réu (que deverá ter legitimidade passiva). A parte, mesmo sem ser legítima ou mesmo sem interesse jurídico, pode exercer o direito subjetivo de ação, que relação processual existirá; da mesma maneira é possível que a parte legítima acione o Estado-Juiz e este cite sujeito que não é parte legítima, que mesmo assim este integrará a relação processual.

Via de regra os sujeitos-de-direito que estavam em relação jurídica de direito material (consequente da norma primária), serão partes legítimas para figurarem como Autor e Réu em suas respectivas relações processuais. Deve haver essa correspondência. Os sujeitos Autor e Réu devem ter constituído um vínculo de direito material antes da constituição da relação processual. A legitimidade, então, é essa correspondência que há entre as posições de Autor e Réu na relação jurídica processual e as posições de sujeito ativo (S') e sujeito passivo (S') na relação jurídica de direito material. Quando houver essa coincidência entre os sujeitos-de-direito da relação material e entre as partes da relação processual, há a chamada legitimidade ordinária. A parte ilegítima, então, é aquela parte que não participou da relação jurídica de direito material (consequente da norma primária), a partir da perspectiva da legitimidade ordinária, destaque-se.

Ocorre que em alguns casos a parte que é legítima não participou da relação jurídica de direito material. É o fenômeno da substituição processual, ou legitimação extraordinária, que ocorre quando $\mathrm{S}^{\prime}$ atua em nome próprio na defesa de direito subjetivo alheio (consequente da norma primária). A substituição processual ocorre, então, quando a parte legítima (termo da relação processual) não participa da relação de direito material. Essa situação só pode ocorrer por permissão expressa do sistema de direito positivo, ou seja, é o sistema que permite as situações em que a substituição pode ocorrer, como no

\footnotetext{
${ }^{36}$ VILANOVA, Lourival. Causalidade e Relação no Direito. 4.ed. São Paulo: Revista dos Tribunais, 2000. p. 204.
} 
caso dos Sindicatos que defendem os direitos subjetivos dos trabalhadores ou do Ministério Público ao mover uma Ação Civil Pública.

O último ponto a ser analisado neste tópico é o que diz respeito ao sujeito $S$ "', das relações processuais, ou seja, o Estado-Juiz. Como dito acima, ele é a intersecção entre as duas relações processuais (S'RS'", e S' 'R'S'”,). Na relação processual primária (Autor e Estado-Juiz) o dever do Estado-Juiz é o de prestação jurisdicional. Na relação processual secundária (Réu e Estado-Juiz) o seu dever jurídico imediato é de citar o Réu. O ato de citar o Réu está abarcado pela classe "prestação jurisdicional" também. Após o ato de citação vários outros deveres surgem, todos abrangidos pelo dever de prestação jurisdicional, como o de oportunizar o contraditório e a ampla defesa. Seja perante o Autor, seja perante o Réu, o dever do Estado-Juiz é o mesmo, qual seja: prestação jurisdicional.

Como dito, a relação processual completa é formada por duas relações processuais. A relação processual primária pode ser representada da seguinte forma, de forma nãoangularizada:

S' $\mathrm{R}^{\prime}$ $S^{\prime \prime}$

Direito subjetivo

Dever jurídico

Os respectivos significados atribuídos aos termos acima são:

$S^{\prime} \equiv$ Autor

$\mathrm{R}^{\prime} \equiv$ functor relacional

$\mathrm{S}^{\prime,}, \equiv$ Estado-Juiz

Direito subjetivo $\equiv$ direito de ação

Dever jurídico $\equiv$ prestação jurisdicional

Já a relação processual secundária pode ser representada da seguinte maneira: S', $\mathrm{R}$ ' $\mathrm{S}$,

$$
\begin{aligned}
& \text { Dever jurrdaco } \\
& \mathrm{S}^{\prime}, \text { ' Estado-Juiz } \\
& \mathrm{R}^{\prime \prime} \equiv \text { functor relacional } \\
& \mathrm{S}^{\prime} \text { ” } \equiv \text { Réu }
\end{aligned}
$$


Dever jurídico $\equiv$ prestação jurisdicional

Direito subjetivo $\equiv$ defesa

Esses são os significados das constantes e das variáveis da relação jurídica processual primária e secundária.

Tomamos como ponto de partida de nossas investigações práticas, e ainda inseridos na problemática significativa, o Código de Processo Civil (linguagem-objeto). O suporte físico "relação jurídica" consta treze vezes no referido suporte físico - CPC - e em todas as suas acepções a "relação jurídica" tem o sentido de consequente da norma primária, ou, relação jurídica de direito material. O CPC não usa "relação jurídica" para designar a relação entre Autor e Estado-Juiz ou entre Estado-Juiz e Réu.

O signo "relação processual” aparece uma vez no CPC, no art. 238. O enunciado constante do referido artigo é "Citação é o ato pelo qual são convocados o réu, o executado ou o interessado para integrar a relação processual.”. O mencionado suporte físico é usado no sentido de relação entre Autor e Estado-Juiz, pois já se afirma que antes de haver o ato “citação", já há relação processual. O sentido empregado pelo CPC é o que nós formalizamos como R'(A,C) e que nomeamos como "relação processual primária".

Muitas vezes o suporte físico "processo", a partir da leitura do CPC, possui o significado de "relação processual". Como é o sujeito cognoscente quem atribui significado aos suportes físicos, podemos afirmar que o sentido "relação processual" é constituído diversas vezes ao longo da leitura do CPC, mas, ressalte-se, o suporte físico "relação processual” aparece apenas uma vez.

\section{V - A relação processual: análise pragmática}

A linguagem também pode ser estudada a partir de sua dimensão pragmática. A pragmática é o segmento da Semiótica que trata da origem dos signos, de seus usos e dos efeitos que eles produzem na conduta. ${ }^{37}$, ou seja, estuda a relação entre a linguagem e o seu utente. Constata-se que a dimensão pragmática abarca tanto a sintática quanto a semântica.

37 GHIGLIANI, Alejandro M.; GUARINONI, Ricardo V.; GUIBOURG, Ricardo A. Introducción al conocimiento científico. 3. ed. Buenos Aires: Eudeba, 2000. P. 65. No original: “(...) puede decirse que la pragmática es la parte de la semiótica que trata del origen de los signos, de sus usos y de los efectos que ellos producen em la conducta dentro de la cual aparecen." 
Iremos focar nossa atenção, neste tópico, a uma das finalidades da relação processual e ao uso que é feito do suporte físico "relação processual" pelo STJ.

O Autor, por meio do documento normativo "petição inicial" instaura a relação processual primária. Com o ato processual "citação" é instaurada a relação processual secundária. Pois bem, mas a relação processual não é um fim em si mesma - daí o caráter instrumental do "processo". Todo processo culmina na criação da norma individual e concreta (sentença). A relação processual é um meio para que se aplique a norma primária. Com a aplicação da norma primária é que o mérito é resolvido ${ }^{38}$, caso haja a aplicação apenas de normas processuais, o processo é resolvido sem resolução de mérito. Da leitura da sentença - qualquer sentença - sempre serão criadas normas jurídicas. A quantidade de normas criadas varia de sentença para sentença. Então sempre o que se objetiva a partir da criação da relação processual, é a constituição de outra relação jurídica (nomeada por nós como "processual-material"), relação, essa constante da sentença judicial. Dito de outra forma: o objetivo do Autor é que a norma primária seja aplicada. Dessa feita, a finalidade da relação processual, a partir dos pressupostos aqui fixados, é a constituição ${ }^{39}$ de outra relação jurídica, que consta da sentença ${ }^{40}$.

Com relação ao uso do signo "relação processual" pelos Tribunais, traremos algumas decisões do Superior Tribunal de Justiça (STJ) onde o mencionado suporte físico é usado. A expressão "não efetivada a relação processual pela citação" da construção teórica aqui realizada, que fora constituída a relação processual primária, mas não a secundária. O que chama a atenção é que o art. 238 do CPC prevê que antes da citação já há relação processual, dessa maneira, a relação processual completa é que não foi estabelecida, mas a relação processual primária já existia. Em caso semelhante ao

\footnotetext{
${ }^{38}$ Resolver o mérito é aplicar a norma primária. Ideia, essa, de Tárek Moysés Moussallem, exposta a mim por meio de diálogos travados com o referido autor.

${ }^{39}$ Não obstante a doutrina processual elencar como espécies de ações de conhecimento as: condenatórias, constitutivas e declaratórias (as mandamentais e executivas em sentido amplo não são espécies adotadas à unanimidade), entende-se, a partir dos pressupostos aqui fixados, que de toda sentença sempre será constituída relação jurídica. Mesmo nas sentenças em que o mérito não é resolvido.

${ }^{40}$ Mesmo as sentenças que não resolvem o mérito constituem relação jurídica. O Réu terá o direito a não ver a pretensão do Autor ser acolhida naquele processo. Esse tema gera grandes repercussões no tema das preclusões.

${ }^{41}$ STJ. AGRAVO INTERNO NO RECURSO EM MANDADO DE SEGURANÇA: AgInt no RMS 49705 PR 2015/0278791-4. Relator: Ministro Gurgel de Faria. DJ: 06/02/2017. Disponível em: 〈www.stj.jus.br >. Acesso em: 31 dez. 2019.
} 
acima exposto, a expressão "não formação da relação processual"42 foi utilizada pelo STJ. Houve, neste caso, a formação da relação processual primária, mas não da secundária. Em último lugar, constatamos o uso da expressão "relação processual ainda não formada" ${ }^{43}$ para designar, também, a existência apenas da relação processual primária. Constata-se que o STJ, nas ocasiões acima expostas, usou o suporte físico "relação processual" com o sentido de "relação processual completa", o que, segundo pensamos, está em desacordo com o CPC, uma vez que este diploma normativo admite a existência de relação processual antes mesmo do ato processual "citação".

\section{CONCLUSÃO}

Nesse escrito a "relação processual" foi analisada a partir de seus planos linguísticos. A conclusão, quando o mencionado signo foi analisado a partir da sintática foi: "relação processual", possui, como toda a relação, a estrutura "R(A,B)". O Autor aciona o Estado-Juiz por meio da "petição inicial", a partir do exercício do direito subjetivo de acionar o Estado-Juiz é constituída a relação processual primária. Com o ato de citação o Estado-Juiz constitui outra relação processual: a secundária " $R(B, C)$ ", onde o Réu a chamado a se defender. Da união dessas duas relações temos a relação processual completa. O que a dogmática processualística nomeia por "relação processual" é, a partir de nossas premissas, a união entre essas duas relações.

A segunda parte da conclusão, que habita o universo semântico da linguagem, diz respeito ao significado do signo "relação processual". Como exposto acima, a relação processual primária é composta por Autor, com direito de ação (direito subjetivo) e EstadoJuiz, com dever de prestação jurisdicional, sendo que este vínculo relacional é constituído por meio do ato "petição inicial". Já a relação processual secundária é composta pelo

\footnotetext{
${ }^{42}$ STJ. AGRAVO REGIMENTAL NO AGRAVO EM RECURSO ESPECIAL. AgRg no AREsp 633833 / GO 2014/0321246-7. Relator: Ministro Luis Felipe Salomão. DJ: 05/03/2015. Disponível em: < www.sti.jus.br >. Acesso em 02 jan. 2020.

${ }^{43}$ STJ. AGRAVO INTERNO NO AGRAVO EM RECURSO ESPECIAL. AgInt no AREsp 720582 MG 2015/0129706-5. Relator: Ministro Sérgio Kukina. DJ: 05/06/2018. Disponível em: < www.stj.jus.br >. Acesso em: 31 dez. 2019.
} 
Estado-Juiz, com dever de prestação jurisdicional e Réu, com o direito subjetivo de defender-se; este vínculo é constituído por meio do ato "citação".

O signo "relação processual" consta uma vez no CPC, no art. 238. O enunciado constante do referido artigo é "Citação é o ato pelo qual são convocados o réu, o executado ou o interessado para integrar a relação processual.”. O mencionado signo é usado no sentido de relação entre Autor e Estado-Juiz, pois já se afirma que antes de haver o ato "citação", já há relação processual. O sentido empregado pelo CPC é o que nós formalizamos como R'(A,C) e que nomeamos como "relação processual primária".

Com relação à dimensão pragmática, constatou-se que a "relação processual" é usada como um meio para que se constitua a relação processual-material; foram analisados alguns julgados do STJ e dessa análise constatou-se que o mencionado Tribunal Superior usa "relação processual" como "relação processual completa".

\section{REFERÊNCIAS:}

ADEODATO, João Maurício. O problema do conhecimento do direito e a proposta retórica realista. DUC IN ALTUM cadernos de direito, v. 9, p. 65-85, 2017

ARAUJO, Clarice von Oertzen de. Semiótica e investigação do Direito. In: Paulo de Barros Carvalho; Aurora Tomazini de Carvalho. (Org.). Constructivismo LógicoSemântico. Volume I. 1ed.São Paulo: Editora Noeses, 2014, v. 1, p. 121-152.

CARVALHO, Paulo de Barros.. Curso de Direito Tributário.22.ed.São Paulo: Saraiva, 2010.

Direito Tributário: linguagem e método.4.ed.São Paulo:Noeses. 2011.

CINTRA, Antonio Carlos de Araújo; DINAMARCO, Cândido Rangel; GRINOVER, Ada Pellegrini. Teoria Geral do Processo. 24ª ed. São Paulo: Malheiros, 2008

DIDIER JR, Fredie. Curso de Direito Processual Civil: introdução ao Direito Processual Civil, parte geral e Processo de Conhecimento. 17.ed. Salvador: Jus Podivm, 2015. V.1.

ECHAVE, Delia; URQUIJO, María; GUIBOURG, Ricardo. Lógica, proposición y norma.1.ed.Buenos Aires: Editorial Astrea, 2002. 
GHIGLIANI, Alejandro M.; GUARINONI, Ricardo V.; GUIBOURG, Ricardo A. Introducción al conocimiento científico. 3. ed. Buenos Aires: Eudeba, 2000.

GOMES, Orlando. Introdução ao Direito Civil. 20.ed. Rio de Janeiro: Forense, 2010.

HAYAKAWA, Samuel. A linguagem no pensamento e na ação. São Paulo: Pioneira, 1977.

MELlO, Marcos Bernardes de. Teoria do fato jurídico: plano da eficácia. $1^{\mathrm{a}}$ parte. 12.ed.São Paulo: Saraiva, 2003.

NINO, Carlos Santiago. Introdução à análise do direito.1.ed.São Paulo: Martins Fontes, 2010, p. $192-196$

SILVA, Yuri de Oliveira Dantas. Anulação e Controle das Normas Jurídicas: uma análise a partir da Ação Direta de Inconstitucionalidade. 1.ed. Campo Grande: Contemplar, 2017.

STJ. AGRAVO INTERNO NO AGRAVO EM RECURSO ESPECIAL. AgInt no AREsp 720582 MG 2015/0129706-5. Relator: Ministro Sérgio Kukina. DJ: 05/06/2018. Disponível em: < www.stj.jus.br >. Acesso em: 31 dez. 2019.

STJ. AGRAVO INTERNO NO RECURSO EM MANDADO DE SEGURANÇA: AgInt no RMS 49705 PR 2015/0278791-4. Relator: Ministro Gurgel de Faria. DJ: 06/02/2017. Disponível em: < www.stj.jus.br >. Acesso em: 31 dez. 2019.

STJ. AGRAVO REGIMENTAL NO AGRAVO EM RECURSO ESPECIAL. AgRg no AREsp 633833 / GO 2014/0321246-7. Relator: Ministro Luis Felipe Salomão. DJ: 05/03/2015. Disponível em: < www.stj.jus.br >. Acesso em 02 jan. 2020.

THEODORO JR, Humberto. Processo Cautelar. 25.ed. São Paulo: LEUD, 2010.

VILANOVA, Lourival. Causalidade e Relação no Direito. 4.ed. São Paulo: Revista dos Tribunais, 2000.

Estruturas Lógicas e o Sistema de Direito Positivo.3.ed.São Paulo: Noeses, 2005 .

Níveis de linguagem em Kelsen. In: . Escritos jurídicos e filosóficos. São Paulo: IBET, 2003.v.2.

WARAT, Luis Alberto. A definição jurídica.1.ed. Porto Alegre: Atrium, 1977. 